\title{
The Stoics on fallacies of equivocation
}

\author{
Susanne Bobzien
}

The Stoics extensively discussed logical paradoxes and fallacies, both of which they would call sophisms ( $\sigma \circ \varphi i \sigma \mu \alpha \tau \alpha)$. They wrote numerous books on the paradoxes of the Liar and the Sorites, which today - again - are the subject of extensive research; they investigated a number of paradoxes and fallacies that are based on puzzles connected with demonstratives, identity, presuppositions and ambiguities, and there are still many questions unanswered about their treatment of each of these. In this paper I take up the Stoic treatment of sophisms or fallacies which contain ambiguities, more precisely which contain an ambiguous word which is responsible for there being a fallacy. In modern terms, these are lexical, as opposed to grammatical or structural, ambiguities, and this kind of fallacy is often

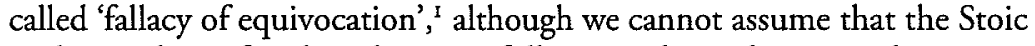
understanding of such ambiguities fully coincides with any modern ones. The Peripatetics called such fallacies fallacies of homonymy, and the Stoics are likely to have called them fallacies of homonymy in single words. ${ }^{2}$ The Stoic discussion of this type of fallacies has been written upon with fruitful results by several scholars, but the precise nature of the Stoic view is still a matter of debate. In this paper, I try to sort out the difficulties for an interpretation of the Stoic treatment of such fallacies based on lexical ambiguities, compare it with Aristotle's treatment of this type of sophisms, and explore what we can learn from it about Stoic theory of logic and language.

I THE EVIDENCE

The central text for the Stoic treatment of fallacies of homonymy is a passage from Simplicius' Commentary on Aristotle's Categories. As there are

${ }^{1}$ Contrasted with 'fallacy of amphiboly' as a name for fallacies of syntactic ambiguity. Hence the title of this paper. The modern names ultimately go back to Aristotle's distinction in the Sophistical Refutations

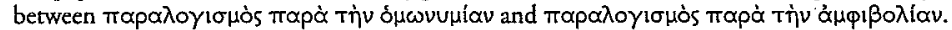

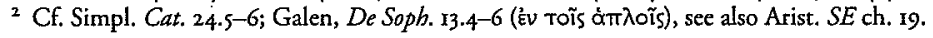


Pr: GQZ

05218418IXc08.xml CUI987B-Frede December 9, $2004 \quad$ 14:4

240

S. BOBZIEN

several ways of translating the text which correspond to several different interpretations, and since to find the best interpretation of the text is one of the goals of this paper, I will refrain from giving a translation here, but rather present the Greek text together with an English paraphrase which leaves open most of the interpretative problems. As the ambiguous word on

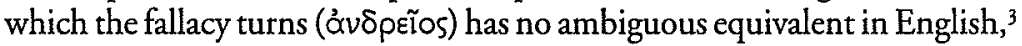
in order to preserve the ambiguity, I will list its two meanings thus: $\{$ for $\mathrm{men} / \mathrm{manly}\}$. The reader is then asked to imagine that this is one word which has those two meanings.

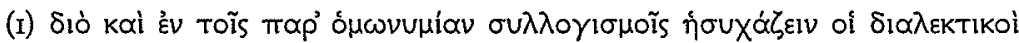

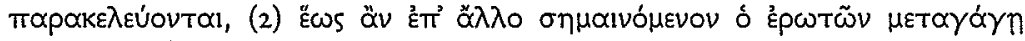

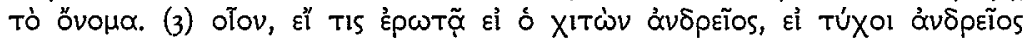

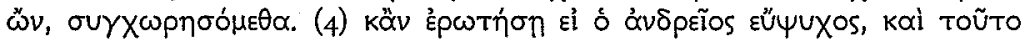

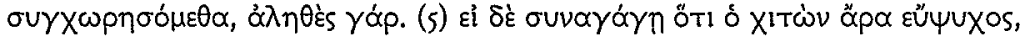

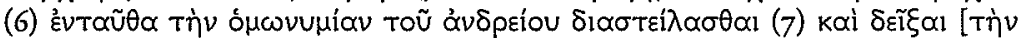

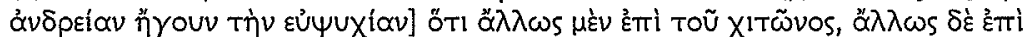

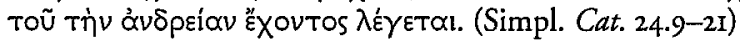

(I) This is why the logicians advise <us $>$ to be silent in the case of syllogisms based on a homonymy. (2) In such syllogisms, at some point the questioner transfers the ambiguous word to another signification. (3) For example, if someone asks whether the garment is $\{$ manly/for men $\}$, if it happens to be $\{$ manly/for men\}, we will concede this. (4) And if he asks whether being \{manly/for men\} is being courageous, we will concede this, too, for it is true. ( 5 ) But if he infers that the garment is therefore courageous, $(6)<$ they advise us $>$ to separate the homonymy of the word ' $\{$ manly/for men $\}$ ' ( 7 ) and show [manliness, that is courage] that it is said or intended in one way in the case of the garment, in another in the case of the one who has manliness.

This passage has given rise not only to a number of different interpretations, but also to some puzzlement. In order to be able to produce a fully satisfactory interpretation and dissolve the difficulties, I start with a brief set of comments on the text, before looking at the philosophical issues it involves. The context of the passage is Simplicius' commentary on Aristotle's definition of homonymy at Categories IaI-2. The problem Simplicius discusses is why, if the topic of the Categories is meaningful speech, not things, Aristotle talks about things which share a name (homonyms) rather

\footnotetext{
3 Common devices to get around this difficulty are substituting the Greek example by a suitable English ambiguous word with a different meaning, or choosing for each occurrence the meaning that is (most likely to be) intended by speaker or listener. Either practice prevents us from an adequate analysis of the text, hence I introduce my - admittedly - awkward nomenclature. (Atherton 1993: 420-I,

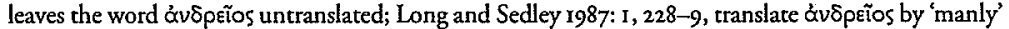
throughout, presumably in the hope that it is close enough to its second meaning 'for men'.)
} 
PI: GQZ

05218418IXco8.xml CU1987B-Frede $\quad$ December 9, $2004 \quad$ 14:4

than, as one would expect, expressions with a multiplicity of significations (homonymies). The 'logicians' are somehow invoked to testify that it is primarily things, and not words, that generate homonymies. ${ }^{4}$ Of course we have no reason to assume that this was the original purpose of the Stoic argumentation reported by Simplicius. ${ }^{5}$

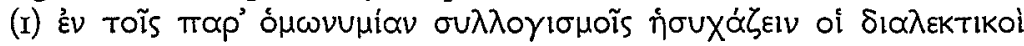

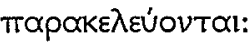

- oi $\delta 1 \propto \lambda \varepsilon k \tau i k o i:$ 'the logicians', 'the dialecticians': Simplicius simply calls the philosophers at issue logicians (or dialecticians). However, there can be little doubt that these logicians were Stoics. ${ }^{6}$ The terminology is Stoic, the method suggested for dealing with the fallacy seems to be Stoic, and most importantly, the example of a simple homonymy we get, that $\alpha \dot{\alpha} \delta \rho \varepsilon \tilde{I}_{0} \mathrm{~s}$ can be said of a shirt and of a man in different meanings, is exactly the one we obtain in Galen's list of Stoic ambiguities.

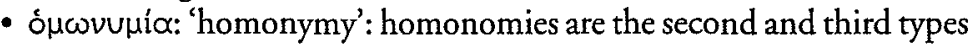
of ambiguities in Galen's list of Stoic types of ambiguities (Gal. De Soph. 13.4-7 Gabler, 22 Ebbesen). At issue in our passage is 'homonomy in single words', ${ }^{7}$ a class in which fall terms that are homonymous in isolation.

- $\sigma u \lambda \lambda \circ \gamma \_\sigma \mu o i:$ 'syllogisms': it is odd that Simplicius (or his source) calls these fallacies syllogisms. For syllogisms are, for Aristotle and the Peripatetics as well as for the Stoics, valid arguments, whereas validity should at least be doubtful in the case of fallacies. There is of course the possibility that the Stoics considered fallacies of equivocation as valid but unsound syllogisms. ${ }^{8}$ More likely, $\sigma \cup \lambda \lambda \circ \gamma / \sigma \mu o$ is not part of the excerpt from the Stoics, but Simplicius' doing. Perhaps this is just carelessness on the part of Simplicius, writing 'syllogism' instead of 'sophism'?

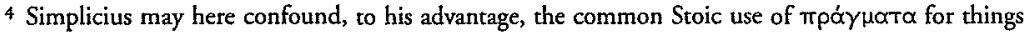
signified (roughly meanings) with the Aristotelian and early Peripateric use of $\pi p o ́ \gamma \mu \alpha T \alpha$ for things.

5 As rightly pointed out by Atherton 1993: 420 n.I4.

${ }^{6}$ So also shown by Atherton 1993: 42I-2.

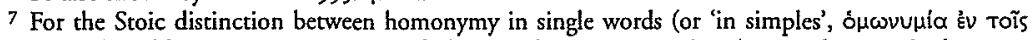

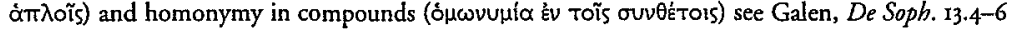
and Atherton 1993: 273-7.

8 There is a Stoic classification that allows for fallacies that are in fact valid (D.L. 7.44, cf. also S.E. P.H. 2.229); but I doubt that the one at issue here belongs in that class.

9 It is possible that - when disregarding the possibility of ambiguity - the Peripatetics considered the linguistic form of the fallacy as a valid form of syllogistic (in a wider sense). Alternatively, 'syllogism' could have been used in the sense of apparent syllogism by Simplicius. For Aristotle writes, at $S E$

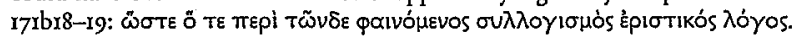


$\mid \begin{aligned} & \text { Pr: GQZ } \\ & \text { 052184I8IXco8.xml } \quad \text { CUr987B-Frede } \quad \text { December 9, } 2004 \quad \text { I4:4 }\end{aligned}$

242

S. BOBZIEN

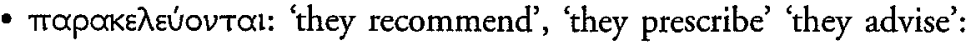
this choice of term, that the logicians recommend a particular strategy, shows that we are in the context of dialectical discourse. Advice is given how to 'play' the dialectical 'game'. So, strictly, this passage does not tell us how the Stoics produce a solution ( $\lambda$ úris) in the case of fallacies of homonymy, although from their recommendation we will be able to venture a good guess what such a solution would have looked like.

- jंouXábalv: 'keep quiet', 'fall silent': what exactly is meant by this expression in this sentence and what its scope is, are matters of controversy. I discuss these questions below in section 7.

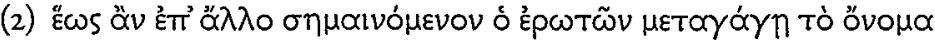

- $\varepsilon \omega s:$ There are three ways of reading this conjunctive expression, and they each lead to different kinds of interpretation of the text: we can either read it as meaning 'until', or as 'while' / 'at the point when', or as 'as long as'. More is said on this in section 7.

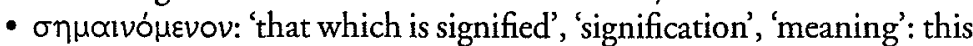
could be Stoic terminology, in which case it refers to what they called 'sayables' ( $\lambda \varepsilon \kappa \tau \alpha$ ) $)$, in this case a predicate, which is an incomplete sayable (D.L. 7.63). Alternatively, $\sigma \eta \mu \propto เ v o ́ \mu \varepsilon v o v$ simply refers to 'that which is signified', in a philosophically neutral sense, as used by logicians in the second century AD and later, including Peripatetics. (There is an ongoing debate in particular regarding Aristotelian philosophy,

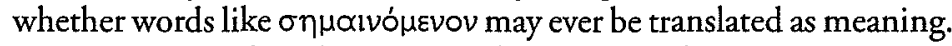
Since it is natural in the context of ambiguity of expressions to talk about the several meanings of a term, and since the Stoic sayables can in a wide sense be considered as meanings, I will talk about the two meanings of an expression, etc. No particular technical slant should be attached to my use of the word 'meaning', though.)

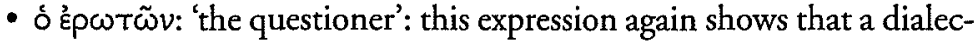
tical discourse is at issue. It involves a questioner and an answerer; the former tries to make the latter contradict himself, or get him into logical trouble otherwise. ${ }^{\text {io }}$

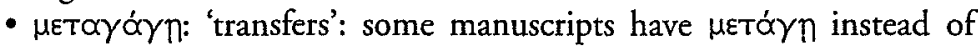
$\mu \varepsilon \tau \propto \gamma \alpha \dot{\gamma} \gamma$. Which reading is preferable depends on the overall interpretation of the passage one chooses. (See below section 7.) Kv has

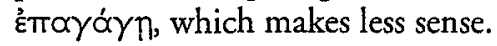

to See e.g. Smith 1997, the introduction, for a good discussion of dialectical discourse and dialectical games. 
\begin{tabular}{|llll} 
Pr: GQZ & & \\
052184I8IXco8.xml & CUI987B-Frede & December 9, 2004 & $14: 4$
\end{tabular}

The Stoics on fallacies of equivocation

- The exact meaning of the whole clause (2) can only be given later. But a translation such as the questioner transfers the word to a different meaning' will prove adequate. In any event, we can infer from (2) that the Stoics held that one word can have more than one signification or meaning, and that users of the word can - somehow - transfer such a word from one of its meanings to another.

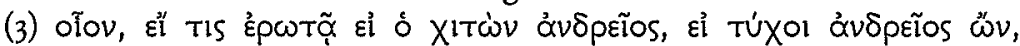

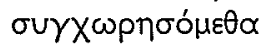

- oĩov: 'for example': this phrase introduces an example of a fallacy of homonymy, and how the Stoics advise us to deal with it.

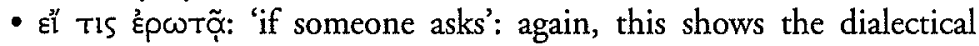
context.

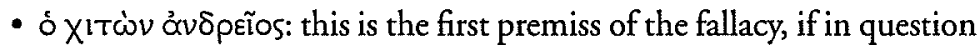
form, though there is in this case in fact no difference in the Greek. We also obtain the first meaning of the ambiguous word ávరpeĩos, namely 'for men', 'of a man', as used e.g. of clothes.

- $\sigma \cup \gamma \times \omega p \eta \sigma o ́ \mu \varepsilon \theta \alpha:$ 'we will agree', 'we will assent', 'we will concede':

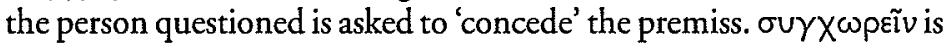
commonly used to describe public, verbal, explicit, assent to a premiss or conclusion, in a dialectical discourse, and more generally. ${ }^{\mathrm{II}} \mathrm{I}$ believe that is the meaning it has in this passage.

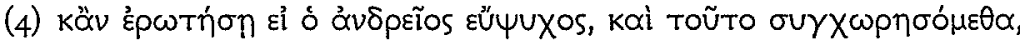

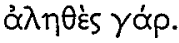

- kờv: 'and if': this conjunction introduces the 'asking' of the second premiss.

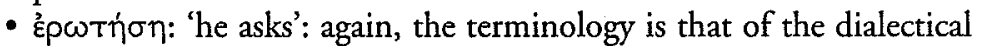
game.

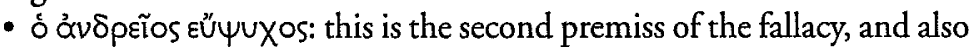
brings in the second meaning of the ambiguous word ớ 'manly', as in 'brave'.

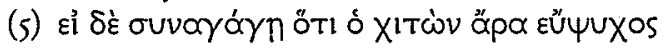

- $\varepsilon \dot{l} \delta \dot{\varepsilon}:$ 'but if': this phrase introduces the conclusion, and its being drawn by the questioner.

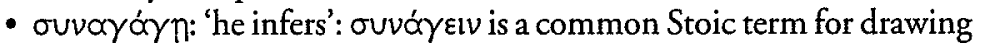
the conclusion of an argument, ${ }^{12}$ but is also used quite generally in ancient logic. ${ }^{\mathrm{I3}}$

\footnotetext{
"I For passages see below note $62 . \quad{ }^{12}$ E.g. S.E. P.H. $2.228,229$; D.L. 7.78.

${ }^{13}$ Alex. AnPr. 2.1, 19.8, 21.28, 22.6, etc.; cf. Arist. Rhet. 135728, 1395b25, Met. 1042a3.
} 


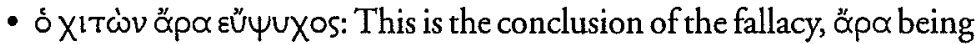
the particle used by the Stoics, and again by ancient philosophers generally, to indicate that a sentence or a proposition is the conclusion of an argument.

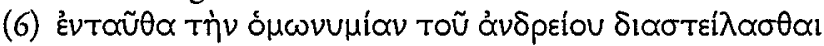

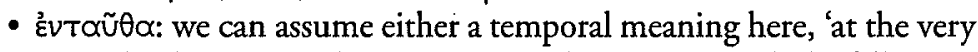
time', 'at this point', 'then', indicating the time at which the fallacious character and elements of the - apparent - argument are meant to be uncovered; or something like 'at this point in the argument'.

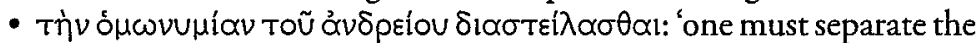
homonymy of " $\{$ manly/for men $\}$ "' (i.e. distinguish the two meanings of the word): $\delta 1 \alpha \sigma \tau \varepsilon i \lambda \alpha \sigma \theta \alpha l$ is used elsewhere to indicate the revealing of the ambiguity of a term. ${ }^{14}$

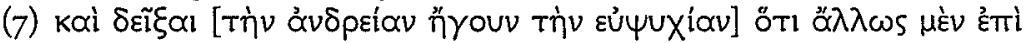

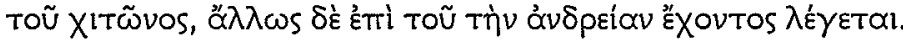

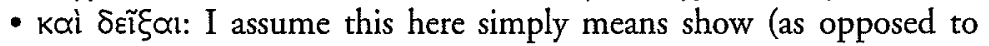
prove in a strict sense); the respondent is meant to show up the double meaning at this point.

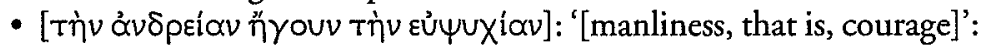
this has been excised by some editors, and indeed it seems somewhat superfluous and out of place; it could have been a marginal note that found its way into the text. Possibly the author of the phrase thought he had better point out that manliness is the same as (or implies) courage, in case this wasn't clear from the fact that being manly implies being courageous.

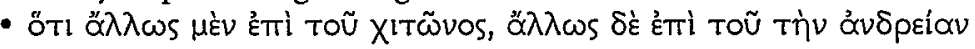
"'XOVTOS $\lambda \dot{\varepsilon} \gamma \varepsilon \tau \alpha$ l: 'that it is said/intended in one way in the case of the garment, in another in the case of the one who has manliness': this clause can be taken in two ways, at two levels of generality; see below, section 4 .

\section{THE FALLACY}

The - or some - Stoics defined ambiguity ( $\left.\alpha \mu \varphi 1 \beta 0 \lambda i \alpha^{\alpha}\right)$ as 'an expression that signifies two or more things in its common linguistic use and in its proper senses and in the same linguistic idiom, so that the several things are

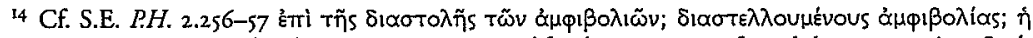

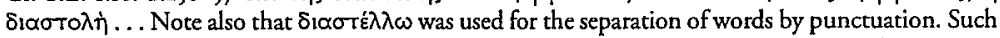
separation is essential for solving structural ambiguities, such as those the Stoics called homonomy of compounds. 
Pr: GQZ

05218418IXco8.xml CUr987B-Frede December 9, $2004 \quad$ 14:4

The Stoics on fallacies of equivocation

understood simultaneously in this expression'. Is Homonymy (¿ $\mu \omega v \cup \mu i \alpha)$

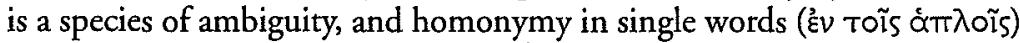
is one of two kinds of homonymy. ${ }^{16}$ Ideally, the ambiguous expression on which the fallacious character of a fallacy of equivocation is grounded should satisfy the Stoic definition of ambiguity. In our fallacy, the Greek word ' $\alpha \delta \delta p \varepsilon i 0 s$, with its two meanings 'for men' and 'manly' appears to do so at least when it is considered in isolation. The word has both meanings in its common linguistic use, i.e. neither is a technical or otherwise unusual expression; in its proper senses, i.e. not metaphorically; and in the same linguistic idiom; and it has the meanings at the same time. Moreover, Galen presents it as paradigm for Stoics ambiguities in single words. ${ }^{17}$

The Simplicius text allows us to reconstruct the fallacy with some certainty:

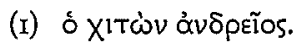

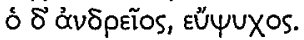

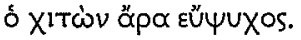

This fallacy (as the majority of Greek fallacies) cannot be straightforwardly translated into English without losing its sophistic character. In order to retain it, instead of translating the ambiguous expressions, I will list their two meanings, as indicated in section $\mathrm{I}$, thus: $\{$ for $\mathrm{men} / \mathrm{manly}\}$, and invite the reader to imagine that this is one word which has those two meanings.

The garment is $\{$ for men/manly $\}$.

But $\{$ what/who $\}$ is $\{$ for men/manly $\}$ is courageous.

Therefore, the garment is courageous.

This triplet of sentences is indeed a fallacy, since what seem to be the premisses appear to be true and to entail the conclusion, which in turn is clearly false. The fallacy does not have the form of a Stoic syllogism. I here speak of the linguistic form of the fallacy, i.e. the three grammatical sentences, and disregard any ambiguities in expressions. ${ }^{18}$ We would get a fallacy with a linguistic form the Stoics may have accepted as that of a valid argument by making slight changes: ${ }^{\text {I? }}$

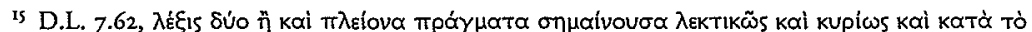

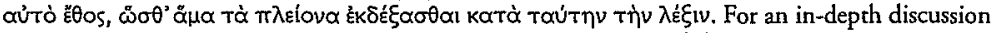
of this definition see Atherton 1993: 135-72. My understanding of the definition owes much to Atherton,

${ }_{16}$ Galen, De Soph. 13.4-7, see above, note 6. ${ }^{17}$ Gal. De Soph. 13.4-5 Gabler, 22 Ebbesen.

I8 Although in the Stoic view syllogisms are not linguistic items (see section 3), we recognise their form in the way they are expressed in language; for this to be possible, the Stoics introduced various kinds of language regulations.

19 See Atherton 1993: 420, n.15 for a different suggestion. 


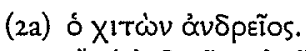

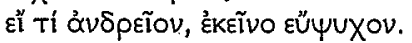

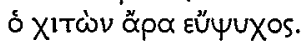

The garment is $\{$ for men/manly\}.

If something is $\{$ for men/manly $\}$, it is courageous.

Therefore, the garment is courageous.

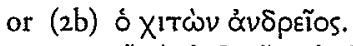
हौ Tí ớ

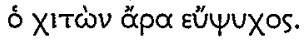

The garment is $\{$ for men/manly $\}$.

If someone is $\{$ for men/manly\}, that one is courageous

- Therefore, the garment is courageous.

Or, with the more common order of the sentences that express the premisses: $^{20}$

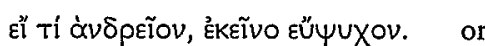

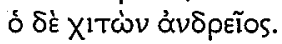

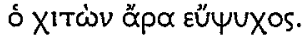

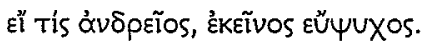

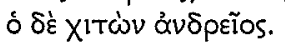

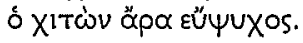

If something is $\{$ for men/manly\}, it is courageous.

If someone is $\{$ for men/manly\}, that one is courageous.

The garment is $\{$ for men/manly\}.

Therefore, the garment is courageous.

The garment is $\{$ for men/manly \}.

Therefore, the garment is courageous.

This still does not have the exact form of a Stoic indemonstrable argument, ${ }^{2 \mathrm{I}}$ but there is some evidence that arguments of this form (not fallacies, of course) were accepted by the Stoics as valid. ${ }^{22}$ The fallacy can be seen as an abbreviating reformulation of this argument which would retain the validity. ${ }^{23}$ We can see why the fallacy was presented as (I) rather than any of the versions of (2). For in the case of (2), a decision has to be made whether to use (2a) 'something' ( $(\mathrm{i})$ ), etc., or ( $2 \mathrm{~b}$ ) 'someone' ( $(\mathrm{i} i \mathrm{~s})$, etc. But (2b) would be understood by a Greek speaker as being clearly about persons, and thus the lack of connection with the first (simple) premiss would be too obvious;

${ }^{20}$ For the Stoics, the order of the premisses did not matter for whether something is a syllogism, and presumably a valid argument, see Bobzien 1996: 181 (premiss permutation) together with $\times 36$ and I52. Nonecheless, customarily the simple premiss would not be placed first in a syllogism.

${ }^{21}$ For the Stoic indemonstrables see D.L. 7.79-81, S.E. P.H. 2.157-8, and Bobzien 1996: 134-41.

22 Cf. Augustine Dial. nIr.84-6 (Pinborg) for an example; see also Cic. Fat. II-I5. For Stoic indefinite conditionals see S.E. $M$. Ir.8, 10, II; D.L. 7.75 and Bobzien 1999: 155-6.

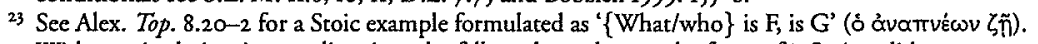
With manipulation in one direction, the fallacy thus takes on the form of a Stoic valid argument; with slighr modification in another direction, it takes on a form considered valid by the Peripatetics:

This garment is $\{$ for men/manly\}.

This garment is \{for men/manly\}.

What is $\{$ for men/manly $\}$ is courageous. All things $\{$ for men/manly $\}$ are courageous.

Therefore, this garment is courageous. Therefore, this garment is courageous.

This fact is insofar as it shows that the fallacy could have been used and been of interest to both philosophical schools, see also section 6 below. (Interestingly, Alexander in the Topics passage $\longrightarrow$ significant

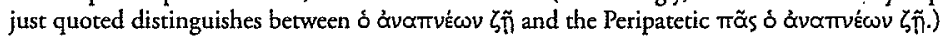


whereas in the case (2a), the sentence would sound somewhat funny, since

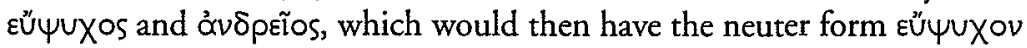
and '̊́vpeiov (in the required meaning of 'manly'), really make sense only for persons.

By contrast, the formulation in the text, i.e. (I), ' $\{$ What $/$ who $\}$ is $\{$ for

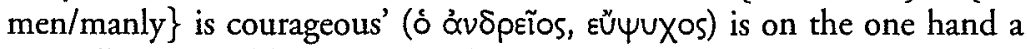
generally accepted 'synonymous' linguistic variant of the sense-making 'If

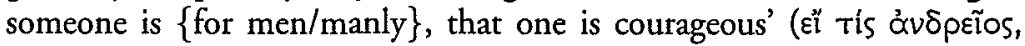

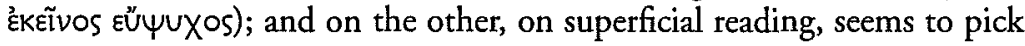
up the o ('the') from $\delta X^{1} T \dot{\omega} v$ ('the garment') in the first premiss, so that there is at least an apparent connection between the premisses. It becomes clear here that it is essential for the fallacy to work smoothly that the word for a garment chosen is masculine. In this way the whole argument goes through with the masculine forms, and its deceptive nature is harder to pin down. Of course, the main element which makes the argument fallacious is the ambiguous word ' $\{$ for men/manly\}'. But as most good fallacies, this one, too, employs more than one device to trick the listener. Sometimes they are cooperative in producing the illusion of soundness or validity, as in this case; sometimes they seem to be introduced into the sophism to distract us from the main fallacious element; and the function of some elements of deception can be interpreted either way.

\section{WHAT SORT OF THING THE STOICS THOUGHT A FALLACY}

\section{OF HOMONYMY IS}

For the Stoics, an argument is a compound of premisses and conclusion. Premisses and conclusion are assertibles or propositions ( $\left.{ }^{3} \xi 1 \omega^{\prime} \cup \alpha \tau \alpha\right)$, and as such incorporeal entities. ${ }^{24}$ They are things signified (or significa-

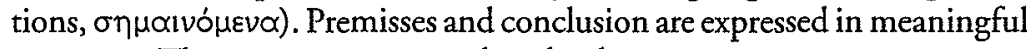
sentences. Thus, we may assume that the three sentences

'If it is day, it is light', 'It is day' and 'It is light'

express the three assertibles or propositions

IF IT IS DAY, IT IS LIGHT, IT IS DAY and IT IS LIGHT.

When such sentences are meant to express an argument (a compound of premisses and conclusion) the Stoics usually indicate this further by particles as follows

${ }^{24}$ They have, however, in principle the ability to change their truth-value and modal properties over time. See Bobzien 1999: 93-6, 1r7. 
Pr: GQZ

052184181Xco8.xml CU1987B-Frede December 9, $2004 \quad 14: 4$

248

S. BOBZIEN

'If it is day, it is light', 'But it is day', 'Therefore, it is light.' These sentences, taken together, express a Stoic first indemonstrable syllogism. What then is the relation between arguments and fallacies, and what is a fallacy in the Stoic view? The Stoics classify the discussion of fallacies under logic, i.e. that part of dialectics $(\delta 1 \propto \lambda \varepsilon \kappa T ı k \eta \dot{)})$ that deals with the things signified. On the other hand, ambiguities are discussed in that part of dialectics that is concerned with language, utterances or speech ( $\varphi \omega \vee \eta$ ). From this fact alone, we can surmise that the Stoic treatment of fallacies of ambiguity draws on both these parts of dialectics.

As Atherton rightly emphasises, ${ }^{25}$ a fallacy of homonymy cannot be (just) an argument, as an argument on its own cannot be fallacious for reasons of ambiguity. For arguments, being at the level of sayables and assertibles, cannot contain ambiguities, whereas the fallacies we are interested in here are fallacies based on ambiguity. So the fallacy must comprise both elements from the level of meanings or things signified and linguistic elements. It arises as a result of incongruities between the two, which are made use of in a cunning way by the designer or proponent of the fallacy.

Our fallacy, for instance, comprises at least the assertibles that THE GARMENT IS FOR MEN, that WHAT ${ }^{26}$ IS MANLY IS COURAGEOUS, that THE GARMENT IS MANLY, that THE GARMENT IS COURAGEOUS, and the argument THE GARMENT IS MANLY, BUT WHAT IS MANLY IS COURAgEOUS, THEREFORE THE GARMENT IS COURAgEOUS. It comprises the sentences 'the garment is $\{$ for men/manly\}', '<but $>$ $\{$ who/what $\}$ is $\{$ for men/manly $\}$ is courageous', and '<therefore $>$ the garment is courageous', and it comprises them in that order, so that they have the appearance of expressing an argument. This complex of meaning items and linguistic items is a fallacy, because it gives, at least at superficial perusal, the impression of being a bit of language expressing a valid and sound argument, but in fact is not. (Naturally, one can discuss sayables and arguments only when they are clad in language; there is no other option. Hence, in principle, ambiguities are always a possibility, and consequently, so are fallacies.)

From a Stoic perspective, fallacies of homonymy thus straddle the realm of meaning and the realm of linguistic expression; however, they also involve the realm of pragmatics. They are the result of an interplay between the first two, based on contingent facts about language (ambiguities), and the intentional use $\mathrm{e}^{27}$ of linguistic items to express meaning items in such a way

${ }^{25}$ Atherton 1993: 413. ${ }^{26} \mathrm{Or}$ 'who', see previous section.

27 Possibly, initially the use is unintentional. 
that they appear to represent validity and soundness, but in fact do not. ${ }^{28}$ Hence they also essentially involve a pragmatic component: a fallacy will only exist if someone has actually formulated and entertained it. (Unlike Stoic propositions, which, at least in the prevalent interpretation, are there even when not in use, ${ }^{29}$ for the Stoics, linguistic items only exist when they are actually used by speakers or writers or thinkers.) Moreover, without the potential to deceive, they are not fallacies $\left(\sigma \circ \sigma_{i}(\sigma \mu \alpha \tau \alpha) .^{30}\right.$ But being (able to be) deceived is a psychological disposition that can be reduced neither to language nor to 'meaning'.

It does not follow that, for the Stoics, fallacies are 'tokens', fleeting occurrences in time, temporary complexes of significations (meanings) and linguistic items. For, the Stoics talk about many fallacies as the so-and-so argument'. ${ }^{31}$ Thus, as in the case of arguments, there are tokens of them, performances of them, if you want, but the fallacies themselves are not just such tokens, and are not reducible to such tokens or performances. We can identify the fallacy with its type. But note that this type is an abstraction,

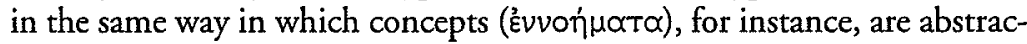
tions for the Stoics, and are not something that has the status of a subsisting entity, as Stoic sayables and assertibles, but are only quasi-somethings. ${ }^{32}$

\section{THE STOIC ADVICE AND CONTEXTUAL DISAMBIGUATION}

Simplicius' Stoics advise that the answerer concede both premisses, and each time they give a reason why and when they should be conceded. The justifications why we should concede the premisses are most interesting. In the case of the first premiss, we are told to consent to the proposition expressed

${ }^{28}$ The Stoics seem also to have allowed for sophisms that are valid, but do not appear to be, cf. S.E. P.H. 2.229, but our fallacy does not belong to this special group.

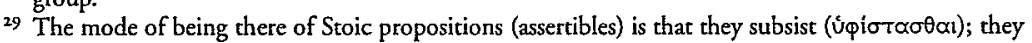
resemble Frege's thoughts or Carnap's propositions in that respect. For the prevalent interpretation see e.g. Frede 1994a, Schubert x994: ch. I, Barnes 1999: 2I, Bobzien r998: 2I-6.

30 I use 'fallacy' as translation of the Greek $\sigma \delta \varphi_{1 \sigma} \sigma \alpha$; the meaning of the latter does not entirely coincide with the meaning of 'fallacy' as used in contemporary English.

31 Thus the Stoics talk about the Idle argument ('ápyòs $\lambda$ óyo5, Origen Cels. 342.62-3), the Master

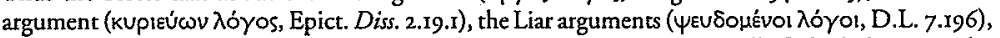

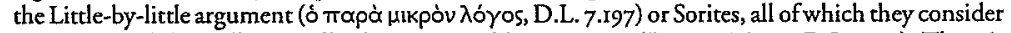
sophisms, and they talk generally about intractable arguments (ớtropoi $\lambda o ́ \gamma o$, D.L. 7.82). There is a problem here, as strictly speaking, for the Stoics even $\lambda$ ó $\gamma$ os, i.e. argument, would be an incorrect description, as a fallacy is not occurring at the level of arguments, but at the level of the relation between linguistic expressions and propositions. Still, they may have called the fallacies so-and-so arguments because they were known under those names before the Stoics tried their hands at them; or alternatively, 'argument' is used in the loose sense of 'apparent argument'.

${ }_{32}$ Cf. Stob. 1.136.21-137.6. 
in the sentence 'the garment is $\{$ manly/for men $\}$ ', if the garment happens to be $\{$ manly/for men $\}$. From this we learn the following: the expression 'the garment' is used demonstratively in the argument; the assumption is that the premiss is true if 'the garment' (together with an act of pointing) is used to 'demonstrate', or refer to, a garment that is $\{$ manly/for men $\}$. At first sight, this is just an application of the Stoic truth-criterion for definite propositions as we find it in Sextus Empiricus. ${ }^{33}$ But there is more to it. The assumption that the premiss is true if the garment is $\{$ manly/for men\} allows us to infer that the Stoics understand the meaning of the expression ' $\{$ manly/for men\}' in this premiss to be FOR MEN. (For the proposition that THE GARMENT IS MANLY would never be true, and at the level of truth, which is the level of sayables and propositions, there is no room for ambiguity. $)^{34}$ Thus there is, at the time when the first premiss is requested, only one proposition expressed by the sentence the garment is \{manly/for men\}', and that is that THE GARMENT WHICH IS DEMONSTRATED IS FOR MEN . ${ }^{35}$ Possibly, the Stoics also thought that only this one proposition was intended by speaker and listener; however, this is a different point. Which proposition or propositions are expressed by a sentence appears to be in principle independent of speaker and listener intention.

The case of the second premiss is even more straightforward. We are advised to concede the second premiss 'because it is true'. Now the sentence ' $\{$ who/what $\}$ is $\{$ manly/for men $\}$ is courageous' can be used to express a truth only if the expression ' $\{$ manly/for men $\}$ ' has the meaning MANLY. Thus the Stoics assume - at least for the purpose of treating the fallacy that the sentence, when asked, is not ambiguous, ${ }^{36}$ and hence that the word ' $\left\{\right.$ manly/for men\}' qua being used in the sentence is not ambiguous. ${ }^{37} \mathrm{We}$ can take it that the premiss would count as a true Stoic conditional, ${ }^{38}$ and thus that - unlike in the case of the first premiss - its truth-value is not context $f$ or time-dependent. Again, speaker and listener intention were

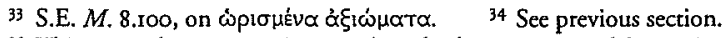

35 This is worth noting on its own, but also because Aristodle's position on this point is different, see below section 6 .

${ }^{36}$ I am not sure whether the Stoics would call a whole sentence 'ambiguous' (å $\left.\mu \phi i ́ \beta \circ \lambda \circ s\right)$, if it contains an ambiguous expression that is not disambiguated by its linguistic context (for examples see section 8 below), or whether they would reserve the term 'ambiguity' for the largest phrase in such a sentence that can be taken in more than one way. If the latter, a more careful formulation, such as 'the sentence, when and as being asked, does not contain an ambiguity', may be preferable.

37 The word ' $\{$ manly/for men\}' as used in the sentence is not such that 'several things are understood simultaneously in this' word, and thus does not satisfy the Stoic definition of ambiguity preserved at D.L. 7.62, for which see section 2 above.

${ }^{38}$ It would be what the Stoics called an indefinite conditional, see above note 22 . For their truthconditions see Bobzien 1999: 112-13. 
likely to be taken to coincide, this time in their both intending the meaning MANLY; again, it does not follow that for the Stoics it depends on the speaker or listener intention what proposition is expressed by the premiss sentence.

This treatment of the two premisses by the Stoics suggests that they endorsed an interesting theory of ambiguity. One way of describing it would be that they assume that context disambiguates. In order not to misinterpret the Stoics here, it is useful to make the following distinction. When I say 'the context disambiguates' I mean by this an entirely non-psychological, non-mental fact: whereas an expression or phrase considered on its own, out of context or without a context, linguistic or otherwise, may be ambiguous in the Stoic understanding, when it is used in a certain kind of context (e.g. a context in which one of two meanings clearly produces a truth, the other clearly a falsehood, and the context ensures that a true statement is intended), it is no longer ambiguous in that sense. It is no longer the case that 'several things are understood simultaneously in this' expression or phrase. From this 'disambiguation by context' I wish to distinguish 'the mental process of disambiguation by speaker and/or listener'. Such a process involves that the person at issue runs in their mind (whether they are fully aware of it or not) through two or more meanings of an expression or clause, and, e.g. as a result of assessing the context, discards all but one of them; eliminates all the irrelevant meanings and retains only the relevant one. These two notions of disambiguation, although they each tend to involve context, are very different things.

It seems to me born out by our text that the abstract observation that context disambiguates was part of the Stoic theory. Thus in Stoic philosophy of language a distinction is required between (i) an ambiguous expression, which is considered on its own to always have simultaneous semantic multiplicity, and (ii) a sentence uttered at a time $t$ which contains an ambiguous expression, but which at $t$ may express only one proposition, and thus involve only one meaning of the expression - despite the fact that even at $t$ the expression considered on its own has its two meanings. I assume that the Stoics took most such sentences to express at most times only one proposition (the same one each time)..$^{39}$ In fact, Augustine, in his work On Dialectic, provides a distinction similar to this one, which may well go back to the Stoics: ${ }^{\circ}$

${ }^{39}$ Neither (i) nor (ii) require reference to speaker's intentions.

40 Cf. Ebbesen I981: I, 32, Atherton 1993: 289-90; Catherine Arherton has confirmed in conversation that on page 290, lines 8-10, in the sentence 'the second <argument> could also be Stoic' she refers to the argument I quote. 
$\mid \begin{aligned} & \text { PI: GQZ } \\ & \text { 052I84I8IXco8.xml } \quad \text { CU1987B-Frede } \quad \text { December 9, 2004 I4:4 }\end{aligned}$

252

S. BOBZIEN

(I) For when it is said that every word is ambiguous, this is said about single (separate, individual) words. . . . (2) And yet, while every word is ambiguous, nobody explains the ambiguity of the words with anything but words (3) Fol as, if I pid 'every soldier is two-footed', it wouldn't follow from this that a cohort of two-footed soldiers was therefore two-footed, so when I say that every word is ambiguous, I don't say that $>$ sentence or discourse $<$ is ambiguous $>$, despite the fact that they are compounded from fwords. ${ }^{4 \mathrm{I}}$ (Dial. ch. 9)

As context for the argument in sentences (2) and (3) we have to imagine an opponent of the Stoic view that every word is ambiguous arguing somewhat as follows: if every word is ambiguous, then you can never disambiguate; for you disambiguate with words; but they are by assumption all ambiguous. The explicitly stated defence of the Stoic view in sentence (2) is that disambiguation of a word $w$ is done not by providing a single word for each meaning of $w$, but by using a plurality of words compounded into a phrase or sentence. Underlying this response is the assumption that whole phrases or sentences, although consisting of nothing but - ambiguous - words, are themselves not ambiguous, or at least need not be. Sentence (3) uses the soldier analogy to make the logical point that from the fact that something is truly predicated of each of a group of individuals it does not follow that one can truly predicate it of the group as a whole. ${ }^{42}$ Thus, if one can truly predicate of each word in a phrase or sentence that it is ambiguous, it does not follow that the group of words as a whole (the phrase or sentence or discourse) is ambiguous. Pertinent to my argument is the underlying assumption in this passage that from the fact that an individual word is ambiguous (has more than one meaning) it does not follow that a whole sentence or phrase which contains this word is ambiguous (has more than one meaning). This is similar to what the Simplicius passage implies about sentences which contain ambiguous words.

However, it follows neither from the Simplicius nor from the Augustine passage that whenever an ambiguous word or phrase is embedded in a sentence, it is thereby disambiguated by context. Some linguistic contexts retain the ambiguity (see also section 8 below). Moreover, presumably for most sentences a non-linguistic context could be imagined in which the disambiguation by linguistic context is countered or undone, as it were. In

${ }^{11}$ Quod enim dictum est omne verbum esse ambigutom de verbis singulis dictum est. . . . (2) Et tamen cum omne verbum ambiguum sit, nemo verborum ambiguitatem nisi sed iam coniunctis quae ambigua non erunt explicabit. (3) Ut enim, si dicerem 'omnis miles bipes est', non ex eo sequeretur ut cohors ex militibus utique bipedibus ita constaret, ita, cum dico ambiguum esse omne verbum, non dico sententiam, non disputationem, quamvis verba ista texantur.

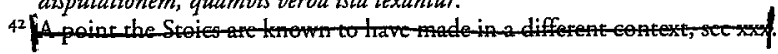

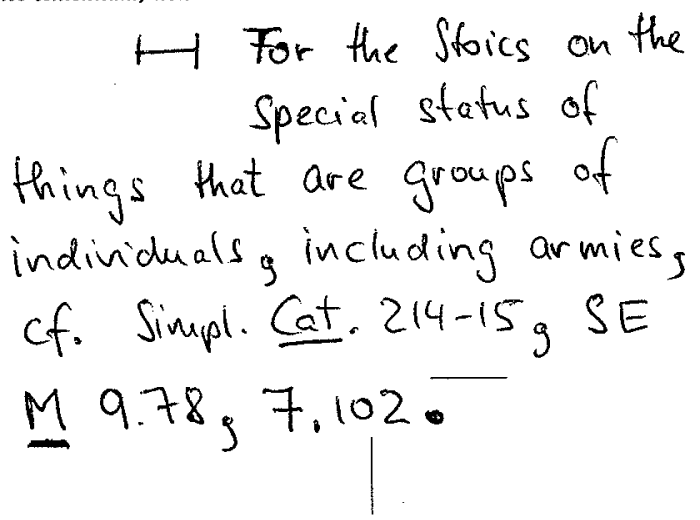


such cases a mental process of disambiguation would be likely to occur in the listener. However, I am doubtful whether the Stoics thought that there occurred in cases like our fallacy mental processes in which an elimination of the irrelevant meanings of the expression at issue takes place. Our evidence is certainly compatible with the assumption that the Stoics took it that, as long as there is no strong contextual pressure to the contrary, no such elimination process takes place, and thus no process of disambiguation, simply because no more than one meaning ever presents itself to (or is called up by) the mind. They may have thought that when someone utters the sentence 'the garment is $\{$ manly/for men\}', in any ordinary circumstances it just means that the garment is for men, and hence nothing else is considered by either speaker or listener. Of course this does not rule out that in the course of an analysis of the sentence out of context, or at some later time, the other meaning is called up in the mind, and a mental disambiguation process does occur.

Let us finally look at the Stoic advice concerning the concluding sentence of the fallacy. At the point when the questioner draws the conclusion and tries to get the respondent to concede it, too, the respondent is to jib:

(5) But if he infers that the garment is therefore courageous, (6) <they advise us $>$ to separate the homonymy of the word ' $\{$ manly/for men\}' (7) and show that it is said/intended in one way in the case of the garment, in another in the case of the one who has manliness.

It is not expressly stated, but we can take it for granted that the Stoics do not want the respondent to concede the conclusion. Rather, at this point, the respondent is to state that the word ' $\{$ manly/for men\}' is used differently in each premiss.

The that-clause (ö $\mathrm{Tl}$ clause) in (7) can be taken in two ways, at two levels of generality; a point which may be of philosophical interest. Either, this clause is short for: (i) that " $\{$ manly/for men $\}$ " had been taken in one way in the first premiss, and in another in the second premiss' - and that hence the conclusion does not follow. Or, it could be taken more generally: (ii) 'that "\{manly/for men $\}$ ", when said of a garment, generally means one thing (i.e. for men), and when said of someone who has courage or manliness, generally means another thing (i.e. manly)'. In that case, (i) is taken to be implied by this, and thus again, the conclusion has been shown not to follow. The way the truth of the premisses is meant to be taken for granted (see above) suggests to me that the second reading is more likely. It tallies with a theory of ambiguity in which context disambiguates, but in which 
$\mid \begin{aligned} & \text { Pr: GQZ } \\ & \text { o5218418IXco8.xml } \quad \text { CUr987B-Frede } \quad \text { December 9, 2004 } \quad 14: 4\end{aligned}$

254

S. BOBZIEN

no mental process of disambiguation occurs in ordinary circumstances if the linguistic context suggests clearly only one meaning.

\section{HOW THE STOICS WOULD HAVE SOLVED THE FALLACY}

We still need to integrate into our interpretation phrase (2) from the Simplicius passage: 'the questioner transfers the word to another meaning'. Here we are clearly dealing with mental phenomena. The transfer at issue is a mental process. In order for it to be possible that such a transfer occurs, there needs first to be a connection the speaker holds between the word and one of its meanings, then such a connection between the word and its other meaning. This connection could be thought of as speaker intention, in which case what is expressed here is a change of speaker intention.

There are two possibilities as to when this transfer may be thought to take place. The first is: at the time of the drawing of the conclusion, ${ }^{43}$ the second: at the time of the asking of the second premiss. ${ }^{44} \mathrm{I}$ opt for the first. The main disadvantage of the second possibility seems to me that interpreted thus, the phrase does not really contribute anything germane to the way the Stoics want the fallacy to be dealt with. (For a full discussion of this point see below section 7.) If we assume that the transfer of the word to another meaning happens at the point when the questioner draws the conclusion, we can now make sense of it easily, even though this way of looking at things is decidedly different from modern philosophy of language. There are in fact two - parallel - possibilities here: 45

(i) At the point when he draws the conclusion, the questioner transfers the word ' $\{$ manly/for men $\}$ ' in the first premiss from the meaning or predicate FOR MEN to the meaning or predicate MANLY. Why would he do that? Because in this way, there comes to be a valid argument (not formally, but still valid, see above section 2). And a conclusion can only be drawn, if the argument is valid.

We need to distinguish here between the linguistic expression consisting of the three sentences, and the argument expressed, or the three propositions expressed. The linguistic expression appears valid (or more precisely, appears to express a valid argument) all the time - as long as we look at it

43 Adopred by Ebbesen I981: I, 31 ('keep calm until'); Long and Sedley 1987: I, $37 \mathrm{~S}$ (" "become quiescent" until'); FDS rv, frg. I257 ('in dem Moment zu schweigen ... in dem'). But note that Ebbesen and Long and Sedley on the one hand, and Hülser on the other, differ in their interpretation of the

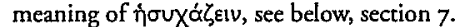

44 Adopted by Atherton 1993: 419-20.

${ }_{45}$ This fact is not mentioned by Ebbesen and Atherton, perhaps because it is of no great relevance. 
without considering the possibility of ambiguity of any of its expressions. However, for the Stoics the bearers of validity are the arguments, not the linguistic expressions thereof, and this point becomes relevant precisely when there is an ambiguity in the linguistic expression. At the point when the conclusion is drawn, the first premiss has become a different proposition (a fourth one), since the word ' $\{$ manly/for men $\}$ ' has been transferred to a different predicate. We now have the new - and false - proposition that THE GARMENT IS MANLY.

(ii) Alternatively, at the point when he draws the conclusion, the questioner transfers the word ' $\{$ manly/for men $\}$ ' in the second premiss from the meaning MANLY to the meaning FOR MEN. Again, there comes to be a valid argument. Again, for the Stoics, it is not the linguistic expression, but what it expresses, that is valid. This argument, evidently, is a different one than in case (i). For now the second premiss has been replaced by a different proposition (a fifth one). ${ }^{46}$ This is the - false - proposition that WHAT IS FOR MEN IS COURAGEOUS. ${ }^{47}$

We cannot say which of the premisses the Stoics assumed the questioner would change. Perhaps they left it open, as it is in the end irrelevant for the solution of the fallacy. Psychologically, it is more likely to be the first. For it is further away, temporally, from the drawing of the conclusion, and hence will be less clear in the listener's mind. ${ }^{8}$ Whether (i) or (ii) was what the Stoics had in mind, or whether they thought it did not matter which, in any event, at the very moment when the word is transferred to the other meaning, the respective premiss of the fallacy becomes a false one. Hence, the conclusion cannot be detached from the premisses, although the argument under consideration has at that point become a valid one. The questioner's hope is of course that the respondent will not be able to figure this out.

Thus the Stoic theory fits well with the - reasonable - assumption that in cases of fallacies, while one concentrates on the premisses, the focus is on the truth of the premisses, while when one draws the conclusion, the focus switches to the validity of the argument. ${ }^{49}$ More importantly for the Stoics, rightly, fallacies based on ambiguity consist not just in the artful choice and manipulation of words or linguistic expressions. Such fallacies work at

${ }_{46}$ The individuation of arguments occurs at the level of propositions ( $\alpha^{2} \xi$ ic $\left.\mu \alpha t \alpha\right)$; and on that level there is no ambiguity.

47 Or that WHOEVER is FOR MEN IS COURAGEOUS

$4^{8}$ Of course, we could switch the premiss sentences round. But as it stands, the fallacy is more likely to confuse the listener (see above, section 2), hence this order of the premiss sentences is presumably not a matter of chance.

49 See Tappenden 1993. 
the level of interaction of meaning and expressions. As long as one looks at the words only, one cannot solve them. As long as one considers solely the level of meaning, they cannot even occur. ${ }^{\text {so }}$

We now have all the information we need to see how the Stoics would presumably - have solved the fallacy. We know that for the Stoics it would not be sufficient, if the respondent just pointed out that the word ' $\{$ manly/for men $\}$ ' in the fallacy is ambiguous; for they, or at least Chrysippus, held that all words are ambiguous. ${ }^{\text {sx }}$ The explanation that would serve as solution ( $\lambda$ Úvi $\left.^{\prime}\right)$ needs to comprise more than that. Catherine Atherton has given the following account of it: ${ }^{52}$

Suppose that a homonym figures in both of the sentences used to signify the premisses of an argument and the contents of the remainders of each sentence ensure that each of the signified propositions will be true if and only if the homonym has a different sense in each, that appropriate to its context. . . The signified argument can be declared false either on the grounds that at least one premiss of this argument is false, although the argument is concludent, or else on the grounds that the premisses of this argument are both true, but, thanks to linguistic expression, (only) appear to have something in common. In the jargon of Stoic logic, this argument is invalid because it is incoherent: the premisses have nothing to do with one another ... But in each case it is a different argument which is being assessed.

This description of what is going on in fallacies of homonomy of the kind the Stoics discussed, including our example in Simplicius, seems to me basically accurate. However, it is what I will call a 'static' analysis of the fallacy, an analysis that looks at the fallacy without considering the factor of time. In order to capture fully what the Stoics think is going on when the fallacy is used in a dialectical context, I believe, a 'dynamic' analysis is more helpful. (I will explicate this presently.) For that, we need to expand the above picture.

In some sense at least, Atherton is clearly correct with her claim that there are two different arguments underlying the sophism. ${ }^{53}$ In the sense that from the various propositions entertained at one time or other by one

so If no distinction is made between premisses and sentences that express premisses; between a level of language at which there is ambiguity, and a level that concerns meaning (whether also linguistic, as Aristotle does, or incorporeal, as the Stoics think), then it becomes difficult to solve the fallacy, i.e. to give a satisfactory explanation of what goes wrong in it. It is possible that the Stoics used this fallacy for more than teaching students to recognise such faulty ways of arguing; they could have used it to show the necessity to distinguish between such levels.

sI Gellius Noct. Att. II.I2.I (LS $37 \mathrm{~N})$; also pointed out by Ebbesen I981: I, 31 .

52 Atherton 1993: 414.

53 Or rather, three, depending on which premiss is taken to be false (see above); but the two arguments with a false premiss would function logically in the same way. 
or the other of the interlocutors two such arguments can be constructed. However, in the Simplicius passage, the argument is developed over a period of time, in an interplay between questioner and answerer, and it repays our effort to investigate when and by whom each argument is entertained. Let me explain:

- At time $t_{\mathrm{I}}$, when the first premiss sentence is proposed and accepted, nothing more than the true proposition THE GARMENT IS FOR MEN is part of the dialectical game. This is the proposition both questioner and answerer appear to intend.

- At time $t_{2}$, when the second premiss sentence is proposed and accepted, either only the true proposition WHOEVER IS MANLY IS COURAGEOUS is at issue, and seems intended by both questioner and answerer, or this one together with the proposition proposed at $t_{I}$, i.e. the pair of propositions.

- Sometime between $t_{2}$ and $t_{3}$, when the conclusion THEREFORE THE GARMENT IS COURAGEOUS is drawn and offered up for approval, the word ' $\{$ manly/for men $\}$ ' is transferred by the questioner to a different meaning, i.e. the questioner moves from the proposition THE GARM ENT IS FOR MEN to the proposition THE GARMENT IS MANLY.54 As a result, at time $t_{3}$ this new proposition is in the game, as only in this way the conclusion can be drawn. And, as the meaning has been transferred, we can assume the old proposition is now no longer entertained by the questioner. As one can only draw a conclusion if one has its premisses present (in some sense), at this point, I assume, the questioner entertains a whole argument, an argument that is valid, but has one false premiss, viz. THE GARMENT IS MANLY.

- What is going on on the side of the respondent between $t_{2}$ and $t_{3}$ and at $\mathrm{t}_{3}$ ? If he is taken in, which is unlikely in the case of so simple a fallacy as ours, he also moves to the other meaning, but without being aware of it. If he is not taken in, we can assume him to resist the move; and in line with the Stoics' advice to point out that ' $\{$ manly/for men $\}$ ' is used in two different meanings in the two propositions that make up the premisses. This suggests that the answerer would not follow the questioner in his transference of meaning, but would insist on taking the premisses to be those propositions that have been agreed upon. And in the two propositions that have been agreed upon, the word "\{manly/for men\}' has different meanings. Thus, for the answerer, the argument assumed to be under discussion is: THE GARMENT IS FOR MEN. BUT

54 Or the questioner does the same with the second premiss, see above. 
WhoEver is Manly is courageous. Therefore the garMENT IS COURAGEOUS. This is an argument with two true premisses and a false conclusion which is invalid for reasons of disconnectedness or

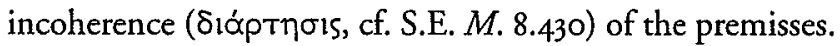

Thus the following picture arises: the questioner, when drawing the conclusion, switches one of the premisses for another which has the same linguistic form, and entertains a valid argument with one false premiss. At the same time his hope must be that the respondent does not notice the transference, sticks to his belief that the premisses are both true, as they certainly were when he agreed to them, and, being befuddled by the appearance of validity of the fallacy, which it has when the possibility of ambiguity is disregarded, feels he has to agree to the conclusion, and thus has lost the game, having had to agree to an obvious falsehood. An answerer trained in Stoic logic, however, will not have been taken in. He knows that linguistically identical sentences can express different propositions. He will not follow the questioner in transferring the meaning of one of the premisses halfway through the argument. He will stick to the propositions he actually agreed to and will reveal that the argument presented is in fact invalid owing to disconnectedness of the premisses. Thus the valid but unsound argument comes in only as a result of the questioner's illicit procedure of transferring meaning within the course of argumentation. The argument that is in fact part of the game, in the sense that its premisses have in fact been agreed upon by both parties, has true premisses and a false conclusion and is invalid.

\section{COMPARISON BETWEEN ARISTOTLE'S AND THE STOICS' TREATMENT OF FALLACIES OF HOMONYMY}

Aristotle, too, discussed fallacies of equivocation or homonymy, and a comparison between his and the Stoic view is instructive. For Aristotle, truthbearers, at least those relevant to sophistic discourse, are linguistic items (Arist. Int. I6a9-Ir, I6b33-17a3). Thus, declarative sentences, and in particular affirmations and negations, are the entities that are either true or false. In the context of dialectics, these declarative sentences are the answers to dialectical questions. For example, if the question is 'Is animal the genus of human?', the possible answers are the affirmative statement 'Animal is the genus of human' and the negative statement 'Animal is not the genus of human'. 'Yes' and 'no' are abbreviations for the affirmative and negative answer respectively. ${ }^{55}$ Aristotle also sometimes says that what is said

s Cf. e.g. Whitraker 1996: ror. 
in a dialectical question is 'true' or 'false'.56 We can assume that what is (in this sense) said in a question could be expressed by the corresponding affirmative statement.

In his Sophistical Refutations, in chapter 17 , Aristotle has this to say about fallacies of homonymy:

If nobody ever made two questions into one question, the fallacy based on homonymy and ambiguity would not have come about, but either a refutation or no refutation. For how does asking whether Callias and Themistocles are musical differ from <what one might ask $>$ if both, though being different people, shared a single name? For if the name signified more than one thing, < the questioner> had asked more than one question. Now, if it is not right to ask to be given without qualification one answer to two questions, it is clear that it is not proper to answer without qualification any homonymous <questions>. (Arist. SE 175b39-176a5, my italics)

Thus, according to Aristotle, if, as in the case of fallacies of homonymy, we have as a premiss or as conclusion a question sentence that contains an ambiguous term, the questioner has asked more than one question: two questions if the term has two significations, three questions if the term has three significations, etc. ${ }^{57}$ In Aristotle's De Interpretatione, chapter 8, we find a parallel passage, in which the focus is on statements rather than on questions:

But if one name is given to two things which do not make up one thing, there is not a single affirmation. Suppose, for example, that one gave the name cloak to horse and to human being; then 'a cloak is white' would not be a single affirmation. For to say this is no different from saying a horse and a human being is white, and this is no different from saying a horse is white and a human being is white. So if these last signify more than one thing and are more than one <affirmation>, clearly the first also signifies either more than one thing or else nothing (for there is nothing like a horse-human-being). (Arist. Int. 18ar8-26, my italics)

As C. W. A. Whittaker has shown nicely, in the De Interpretatione Aristotle discusses affirmations and negations insofar as they are relevant for dialectics. ${ }^{8}$ In the passage quoted, Aristotle discusses cases (which in the Sophistical Refutations he would classify as cases) of homonymy as they would occur in dialectics, i.e. in fallacies of homonymy. ${ }^{59}$ This time, as throughout in De Interpretatione, Aristotle focuses on statements rather than on questions, but his point is basically the same: in dialectics, in the

56 E.g. Arist. Top. r6oa25.

57 There can be absolutely no doubt that in this passage Aristotle has homonyms in mind - he mentions them three times - the third time at the end of the section, at 176 ars.

s8 Whittaker 1996 passim. $\$ 9$ See the passage from $S E$ just quoted. 
Pr: GQZ
052184181Xco8.xml $\quad$ CUx987B-Frede $\quad$ December 9, $2004 \quad$ I4:4

260

S. BOBZIEN

case of declarative sentences that contain what he classifies as homonymies in the Sophistical Refutations there will be more than one affirmation in the sentence. ${ }^{60}$ (This, if the relevant sentence is in the affirmative, otherwise more than one negation.) Thus for Aristotle, in dialectics, (i) someone using a homonymous expression in a question sentence asks two questions, (ii) there are two things said with that question ${ }^{6 \mathrm{I}}$ and (iii) someone using an expression that signifies two things in a declarative sentence makes two statements (two affirmations or two negations). ${ }^{62}$

Returning to our fallacy in Simplicius, in Aristotle's view, the declarative sentence 'the garment is $\{$ manly/for men \}' would hence be more than one affirmation. The two affirmations can be separated in English as (i) 'the garment is for men' and (ii) 'the garment is manly'. The sentence would signify more than one thing (perhaps manliness and for-men-ness; or a garment that is manly and a garment that is for men). ${ }^{63}$ The same holds for questions: the question sentence is the garment $\{$ manly/for men $\}$ ?' would be more than one question; they could be separated in English as is the garment for men?' and 'is the garment manly?'.

Thus, for Aristotle, one declarative sentence is more than one affirmation, one question sentence more than one question. How can this be? Sentences as well as affirmations and questions are linguistic items, but evidently they must be of different kinds, as they are individuated differently. We could say that $b y$ uttering one question sentence the speaker asks two questions; and by uttering one declarative sentence the speaker makes two affirmations or affirms two things. (We can think of the sentences as grammatical items, the affirmations and negations as statements, the questions as questions asked.) So we can expect that whenever the questioner offers

6o Whittaker, following Ackrill, believes that the passage quoted does not cover homonyms. But in the light of (i) the close parallel to the passage quoted from $S E$ (175b39-176as), which explicitly deals with homonyms, and (ii) the fact that Int. deals with dialectics, I have no doubts that in Int. 8 Aristotle intended to cover what in $S E$ he regards to be homonyms as they occur in dialectics. (I argue this point in more detail elsewhere.) For readers who are wedded to Ackrill's view, I mention that for my argument it is sufficient to rely on the passages from $S E$ and $T o p$.

${ }^{61}$ Cf. also Top. r6oa23-9, quoted below.

${ }^{62}$ We can imagine a fallacy pur in declarative sentences rather than questions for instance when someone tries to solve it by himself, at his leisure, without being subjected to questions. Aristotle mentions this possibility e.g. at $S E_{17776-8}$

${ }^{6}$ Unlike Shields 1999: 80-I, n. 8, I take it that in Int. 8 Aristotle uses the verb 'to signify' (18a24, 25)

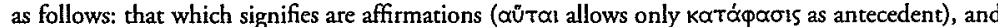
that which is signified by the affirmations are the things referred to by the subject expression in the affirmation - a horse and a human being, or perhaps a white horse and a white human being. The sentence 'a cloak is white' is then said to either both signify horse and signify human being or to signify a horse-human-being, which is nothing; and in the first case the sentence contains two affirmations, in the second no affirmation. 
up for consent the premiss-questions of a fallacy of homonymy which have the same ambiguous expression in either premiss, each time he asks two questions; and if he stated the argument in non-question form, he would each time make two affirmations.

Aristotle discusses ways of responding to fallacies of homonymy in his Sophistical Refutations, chapters 17 and 19. In chapter 19 he begins with some general remarks about such fallacies:

(I) Now, of the refutations that depend upon homonymy and ambiguity some have one of the premiss-questions with more than one signified thing ... e.g. ... in the <argument> that the one who knows does not understand <what he knows> one of the premiss-questions is ambiguous. (2) And that which is said/meant in two ways is in one case <true> and in the other isn't; and that which is said/meant in two ways signifies something that is and something that is not ... (Arist. $S E$ I77a9-15)

I take it from (I) that for Aristotle a premiss-question is ambiguous if it is or contains an expression that signifies more than one thing. In (2), Aristotle seems to pick up on what he said at $S E$ 175b39-176ar8 (quoted above), i.e. that the questioner asks two questions in one, and that the ambiguous expression has two 'signified things' at the same time. ${ }^{64}$ If we apply Aristotle's point to the Simplicius fallacy, the piece of speech 'the garment is $\{$ manly/for men\}' would be said in two ways, even though one way is rather non-sensical. It would be true in one case ('the garment is for men'), but not true in the other ('the garment is manly'). It would signify something that is (perhaps a garment that is for men) and something that is not (perhaps a garment that is manly). ${ }^{65}$

Here are then some passages from chapters $I 7$ and I9 of the Sophistical Refutations and from Topics 8.7, in which Aristotle gives advice how to deal with fallacies of homonymy. They also further corroborate the point that

${ }^{64}$ The first clause of (2) makes sense only if we assume that with the phrase is in one case $<$ true $>$ and

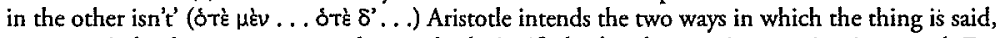
more precisely, these two ways as they are both signified when the premiss-question is utcered. For only then is it reasonable to say that one is (true), the other isn't. If Aristotle had meant to use ठ́tॄ $\mu$ '̇v . . . ót' $\delta$ ' ... temporally, to be translated as at one time . . . at another time . . . or similarly, then we would have expected him to say that both are <true $>$ : i.e. at one time, in one context, one of the two things said in the question sentence is (true), at another time, in another context, the other is (true); that is, that Aristotle would have alerted us to the fact that ambiguous expressions have different meanings in different contexts. But Aristotle does not say that. Thus ótદ̉ $\mu \dot{v} v$. . . ótè $\delta$. . must here be used non-temporally to pick out the two things said by the two questions; only then does what Aristotle says make sense, fit the context, and is true. (Aristotle makes a similar point

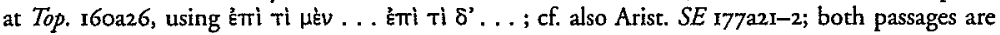
quoted below.)

65 Or alternatively, maybe, the garment's being for men and the garment's being manly? 
he believes that the questioner asks two questions at the same time, and that with the question sentence two things are said at the same time:

... since if someone does not distinguish the $<$ different meanings in the $>$ ambiguity, it is unclear whether he has been refuted or has not been refuted, and since, in the context of arguments, it is granted that he may draw distinctions, it is evident that if he grants the question without drawing distinctions and without qualification, this is a mistake. (Arist. $S E$ I75b28-3I)

Now, if it is not right to ask to be given without qualification one answer to two questions, it is clear that it is not proper to answer without qualification any homonymous <questions>. (Arist. $S E$ i76a3-5)

Now, if one should not give a single answer to two questions, it is evident that in the case of homonyms one should not say 'yes' or 'no' either; for the one who says $<$ that> has not given an answer, he just spoke. (Arist. $S E_{\text {I76ar4-16) }}$

[continuing the quotation from chapter Ig above] ... (3) Whenever <that which is said in several ways $>$ lies in the premiss-questions, it is not necessary to begin by denying that which is said/meant in two ways; for argument is not for the sake of this, but through this. (4) At the beginning one should reply concerning that which is said in two ways, whether it is a word or a phrase, in this way, that in one sense it is so, and in another not so, (5) for example that speaking of the silent is possible in one sense but not in another; and that in one sense one should do what must be done, but not in another; for what must be done is said/meant in several ways. (Arist. $S E$ i77ar8-24)

If $<$ the answerer $>$ understands the question, but it is said in several ways ${ }^{66}$ then... if what is said/meant is in one case false and in the other true, he should indicate that it is said in several ways, and that in one it is false, in the other true. For if he makes the distinction only later, it is unclear whether he saw the ambiguity at the beginning. (Arist. Top. 160a23-o)

These quotes taken together give us some idea about Aristotle's view how one should respond to fallacies based on homonymy. At least one of the question sentences (premiss-questions and conclusions-question) contains an ambiguous expression, and is hence two questions. Answering those two questions with one word ('yes'/'no') or one statement (the affirmative/ negative corresponding to the question) without any qualification and without drawing any distinctions is a mistake ( $\left.S E_{175} \mathrm{~b}_{28-3 \mathrm{I}}\right)$, is not proper ( $S E$ I76a3-5), is no answer at all ( $S E$ I76aI4-16), leaves it unclear whether the answerer noticed the ambiguity (Top. 160a23-9), and leaves it indeterminate which of the two questions the answerer intends to answer. Aristotle reports that according to the rules of dialectics, in addition to saying 'yes' and 'no',

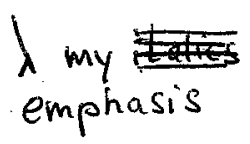

${ }^{66}$ I.e. has several meanings or significations. 
the answerer is allowed to point out ambiguities or to ask for clarification (Top. ch. 8.7 and $S E$ I75b30). Hence the answerer should disambiguate, i.e. should (i) distinguish the two things said in the two questions, and (ii) state which one is true, and which one is false. It is implied, I presume, that (iii) the answerer accepts the true statement and does not accept the false one (cf. e.g. Top. 160a24-8). ${ }^{67}$

Aristotle seems to advise the respondent to expose the ambiguity of a term or phrase immediately when the premiss containing it is 'asked' (see sentence (4) and Top. I60a23-9). ${ }^{68}$ We can understand this as a preemptive move. The answerer explicitly disambiguates the expression, i.e. points out the two - or more - things signified by the question, including those that would be unusual readings of the sentence and false. ${ }^{69}$ (Naturally, this presupposes a mental process of disambiguation.) Aristotle assumes that in the premiss question asked the ambiguous expression has both meanings, even if the respondent intends only one meaning, and even if one meaning makes the premiss false or absurd. For this reason, Aristotle wishes the ambiguity to be made explicit as soon as it occurs. As a result, when the questioner attempts to draw the conclusion, the answerer can fall back on the disambiguation he proffered earlier and refuse to accept the conclusion e.g. by accusing the questioner of a Fallacy of Homonymy or perhaps of a Fallacy of Many Questions. ${ }^{70}$

67 Can the facts (i) that at $S E \times 66 a 4-5$ Aristotle uses ótè $\mu$ èv . . ó ótż $\delta^{3} \ldots$ to explain double meaning, and (ii) that at $S E$ 166a20-1 he uses $\eta$. . . i . . . when saying that an expression signifies two things, be used to rebut my claim that for Atistotle in dialectical contexts question sentences and declarative sentences containing ambiguous expressions have two significations at the same time? I believe not. In note 64 I have shown that Aristotle uses ótغ̇ $\mu \dot{v} \nu \ldots$ ótè $\delta^{\prime} \ldots$. non-temporally for double meaning. At I66a4- 5 he may do just the same. And as in English the two sentences " bank" means both "verge of river" and "financial institution"' and "bank" means either "verge of river" or "financial institution" ' do not usually allow any inference as to whether the speaker assumes that the word has both meanings at the same time, so for Greek sentence with $\eta_{1}$. . i . . . (CF. also in

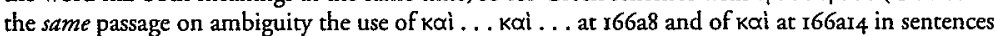
stating double meaning.) Alternatively, one has to assume that what Aristotle says about homonymy in chapter 4 of $S E$ does not tally with what he says in chapters 17 and 19.

68 If the answerer didn't spot the ambiguity immediately, all is not lost. He can still disambiguate at the end. Cf. "However, if < that which is said in two ways > escapes one, one must correct it at the end adding something to the question: "Is speaking of the silent possible?" "No, but it is possible to speak of this person who is being silent".' (Arist. $S E$ r77a24-6) and 'But if he doesn't foresee the ambiguity, but concedes the question having in view the one signification of the words, then, if the questioner takes it with the other signification, he should say: "that was not what I had in view when I conceded it, but rather the other signification"' (Arist. Top. 160a.29-32).

69 Cf. e.g. Arist. $S E$ I66ar2-14: 'speaking of the silent' has as one of its meanings that the one who is speaking is silent; and 166ar8-21: 'knowing letters' has as one of its meanings that the letters have knowledge.

70 In $S E$ chapter 17 Aristotle classifies the fallacy of homonymy as a kind of the fallacy of double question; in chapter 19 he discusses fallacies of homonymy and amphiboly on their own. 
$\mid \begin{aligned} & \text { Pr: GQZ } \\ & \text { o52184181Xco8.xml } \quad \text { CUr987B-Frede } \quad \text { December 9, } 2004 \quad 14: 4\end{aligned}$

264

S. BOBZIEN

If we compare Aristotle and the Stoics, we see that they differ both in their philosophico-linguistic analysis of fallacies of homonymy and consequently - in the strategies they recommend how to tackle them. Aristotle assumes that in the fallacy the question sentences that contain the homonymous expression, when uttered, have two significations, say two things, and have two statements corresponding to them. Usually, but not necessarily, one will be true, the other false. The two significations appear to be independent of speaker intention: for Aristotle considers the case that one can try to solve a fallacy at one's leisure without anybody

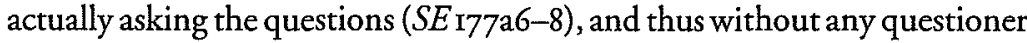
having any intentions. The Stoics, on the other hand, assume that the premiss questions of the fallacy, when uttered, have only one signification: the one which rational speakers and listeners in ordinary circumstances would assume them to have, i.e. usually the meaning that makes them true.

Concerning strategy, in line with his assumption of a double question, Aristotle recommends that the respondent expressly disambiguate the question sentence as soon as it is asked, and to state which question says something true, which not, and presumably which one he accepts. This presupposes a process of mental disambiguation on the side of the respondent. The Stoics, by contrast, do not require an explicit disambiguation, since they assume that at the time of utterance there is in fact nothing to disambiguate. Accordingly, no process of mental disambiguation is required either. The exception would be special situations such as those in which one is trying to list ambiguous sentences, or intends to 'play on' the ambiguity (but not to deceive). For the Stoics, fallacies do not provide such special situations.

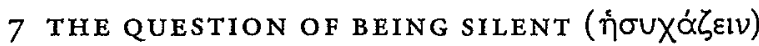

We now have a viable interpretation of what the Stoics of the Simplicius passage considered the nature of the fallacy to be, what philosophical and linguistic assumptions underlie their understanding of the fallacy, and how they recommended the answerer to escape being caught in it. What remains is to give an interpretation of what those Stoics mean when they say the

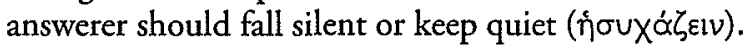

In her masterful book The Stoics on Ambiguity, Catherine Atherton has suggested the following interpretation: She translates: ' $(I$ ') And that is why, in syllogisms due to homonymy, the dialecticians recommend keeping quiet 


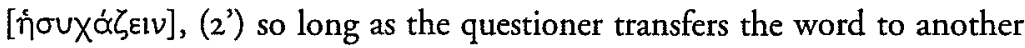
signification. ${ }^{71}$ She comments: 'the transfer to another meaning must occur when the second premiss is posed, not at the conclusion, whereas we "keep quiet" (see the main text) until then, that is, so long as the questioner

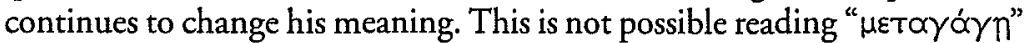
at 24.I4 (i.e., with an aorist subjunctive). I thus read " $\mu \varepsilon т \alpha \dot{\gamma} \gamma$ " with two of the MSS. ${ }^{72}$

After having mentioned the Sorites, Atherton writes further: 'According to Simplicius, respondents are explicitly told to assent to the premisses The tunic is male attire and The brave is courageous. What he failed to note is that they will not make their assent public, and that they will make no contribution to the proceedings, either openly agreeing or openly objecting, until the fraudulent attempt to draw a conclusion. "Keeping quiet" covers, and must cover, silent assent even in the case of the Soritic arguments, since it would be absurd and wrong to withhold assent from the obvious truths leading up to the unclear premisses. As with Soritic arguments, a further assumption is at work: that questioning by the interlocutor will continue until an explicit response, positive or negative, is won. ${ }^{73}$ This view leads her to the following assessment of S.E. P.H. 2.253: 'Sextus' interpretation of

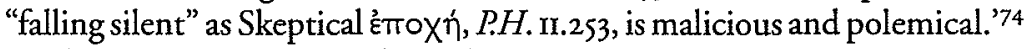

There are some drawbacks to this interpretation:

(i) The occurrence of conceding ( $\sigma \checkmark \gamma \times \omega \rho \tilde{\omega}$ ) $)$ in either premiss has to be understood as silent assent ( $\sigma \cup \gamma K \propto \top \alpha \dot{\theta} \theta \varepsilon \sigma 1 \varsigma) .{ }^{75}$ This seems to me a very unlikely meaning. The term 'to concede' is standardly used for the public action of admitting a premiss or sentence as true, and I believe this is what it means in our passage, too. ${ }^{76}$

(ii) The transfer of the ambiguous word to another meaning is taken to occur when the second premiss is posed. This, too, strikes me as unlikely. First, in this way what Simplicius says seems not to be very relevant to the rest of the passage. He could just as well have said: 'the dialecticians recommend keeping quiet until the conclusion has been drawn'. Moreover, in Atherton's view, the transference is completed after the second premiss has been asked; but, according to her, the silence is only to be broken after the conclusion has been asked.

${ }^{71}$ Atherton 1993: 419-20. $\quad{ }^{72}$ Atherton 1993: 420, n. $14 . \quad{ }^{73}$ Atherton 1993: 422.

74 Atherton 1993: 422 n. 19. 75 Atherton 1993: 422.

${ }^{76}$ See e.g. S.E. P.H. 2.232; M. 8.303; Alex. Apr 17.3, 17.23 (of conclusion); 18.26-7 in a dialectical syllogism, i.e. within dialectical discourse. 
(iii) The assumption is that the questioning by the interlocutor continues even when the respondent remains silent. ${ }^{77}$ There is no evidence that this is how the dialectical discourse went; it seems much more likely that as soon as the respondent refuses to respond 'yes' or 'no' and chooses to keep silent, the 'game' (as conducted on the object level) is over. $^{78}$

(iv) Simplicius has to be interpreted as having left out some essential information (i.e. that keeping quiet covers the case of someone withholding public assent but giving silent assent). Every interpretation that has to state that the author of the passage left out something or got something wrong is weak in that respect, if there are alternative interpretations that do not require this, so that without that requirement the text makes sense and has an equally or more natural reading of the expressions used.

(v) Similarly, an interpretation that does not have to disregard a passage as polemical or malicious is preferable to one that does, if there are no specific requirements to assume that polemics or malice are at work. The cases I have in mind are those where the only reasons for claiming that an author is distorting Stoic doctrine where he reports it (besides the fact that he is a polemical author) is that it vindicates a particular modern interpretation of a bit of Stoic theory, and where there are viable alternative interpretations available for that bit of theory that do not require such a claim of distortion. This is, in my view, the case

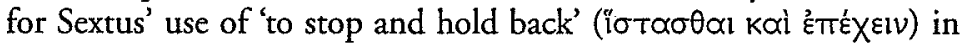
the context of the Sorites at P.H. 2.253. ${ }^{79}$.

77 Long and Sedley's translation of and comments on the Simplicjus passage imply the same assumption (Long and Sedley 1987: I, 228-9; II, 232).

${ }^{88}$ Carneades' response to the Stoic strategy for Sorites arguments at Cic. Acad.Pr. 93 is a case in point that the questioning did nor just continue. He suggests that when the Stoic falls silent at the question 'are n many' someone may come and ask 'and when I add one to the number at which you fell silent, is the result then many?' Hence the assumption is not that the questioning simply continues; rather, Carneades' ficcitious questioner switches to a different type of question. The Stoic would of course simply be silent again, and therewith this type of questioning would have come to an end, too. In the case of Sorites series asked with conditionals or negated conjunctions (as in D.L. 7.82) there is another reason why in the Sorites the questioning would nor have continued: even if only one of the complex premisses has not been assented to, no conclusion can be drawn.

$79 \mathrm{I}$ am in no way denying that Sextus is frequently polemical and malicious in his interpretation or explication of Stoic doctrine. At the same time he is often a very reliable source where he reports or presents Stoic theory - he is one of our best sources for Stoic logic. Wilful misinterpretation is then one thing, wilful misreporting another. In P.H. 2.253, in the sceptical context in which the repor of Chrysippus' view is embedded, Sextus uses 'to hold back' (ėréx 'Ev) twice; each time the context requires that by holding back is intended not answering 'yes' or 'no' to a dialectical question. Nothing is implied about internal suspension of belief, although I believe it likely that explicit and internal holding back were taken to go hand in hand. Thus the most natural reading of 'holding back' in 
Atherton accepts these drawbacks in her interpretation, ${ }^{80}$ because she believes that her interpretation is required in order to overcome the following interpretational difficulties:

(I) There is first her assumption "That in the Sorites "keeping quiet" covers and must cover, silent assent since it would be absurd and wrong to withhold assent from the obvious truths leading up to the unclear premisses.' This difficulty can be solved however. As I have shown elsewhere, ${ }^{8 \mathrm{I}}$ in the Sorites 'keeping quiet' can (and should) be interpreted as openly and publicly ceasing to respond to the questioner's question, with the additional assumption that the answerer does not silently assent either, but is also inwardly quiet. This allows us to interpret Sextus at P.H. 2.253 as not being malicious, but using 'to stop and hold back' ("i $\sigma \tau \alpha \sigma \theta \alpha$ kal

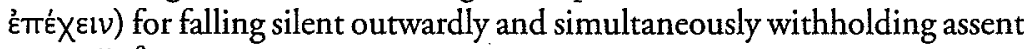
inwardly. ${ }^{82}$

(2) Second, there is Atherton's assumption that, if the Sorites required silent assent, this silent assent was taken to be the required response in

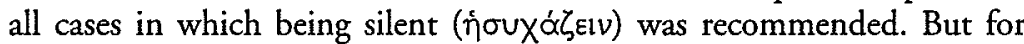
example in Gellius (Noct. Att. 16.2) we find cases of fallacious questions in which falling silent is recommended but internal assent as response is clearly neither required nor desired.

(I) They say that in the art of dialectics there is the following rule: if there is an inquiry and discussion about some thing, and in that context you are asked to answer a question, then you should say nothing more than solely this which is asked, either affirming it or denying it. And those who do not follow this rule and answer either more or something different from what they were asked are regarded as being uneducated and as not observing the customary practice and principle of $<$ dialectical> discourse. (2) In fact, what they say without doubt ought to happen in most debates. ... (4) But there seem to be some cases in which you are caught $<$ in a fallacy $>$, if you answer what you have been asked briefly and to the point.... [there follow examples offallacies in which one would have to say more than 'yes' or 'no' if one wanted not to be caught in them] ... (I2) But such an answer <in which more is said than was asked $>$ is not given in accordance with the above-mentioned rule; for more than what has been asked is answered. (13) For this reason the following

the clause that purports to report Chrysippus is that by it, too, is intended not answering 'yes' or 'no' to a dialectical question. For this clause is used to justify the sceptics' not answering dialecrical questions. Internal suspension of belief is secondary for the entire passage P.H. 2.253. Thus there is no need for Sextus to misreport Chrysippus' view here. Note also that Plutarch, at Adv. Colotem

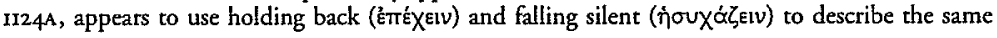
strategy.

${ }^{80}$ I don't wish to imply that Catherine Atherton considered all of (i)-(v) as drawbacks.

8i Bobzien 2002: sections 4-6.

82 It would also bring Sextus in line with Plutarch Adv. Colotem 1124A. 
addition is usually also made to that rule, that one need not answer fallacious questions. ${ }^{83}$ (Gell. Noct. Att. 16.2) ${ }^{84}$

The fact that silent assent would be the wrong reaction in the cases of the Gellius passage seems to me to confirm that it was never part of the strategy of falling silent.

(3) Third, there is Atherton's assumption that in the Simplicius passage 'being silent' is used in the same semi-technical way as in the passages we have about the Sorites (and in my view in Gellius). ${ }^{85}$ This assumption is

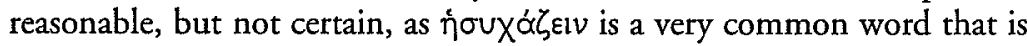
used in Greek in ordinary discourse without any technical overtones.

I will now present two interpretations of the Simplicius passage that do not share the drawbacks Atherton accepts in her interpretation, but at the same time also do not raise the problems she assumes other interpretations will automatically face. Both interpretations assume that the transfer of the word to a different meaning happens when the questioner draws the conclusion (see above section 5 ).

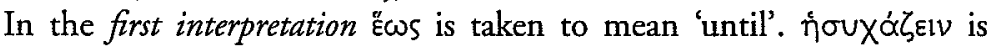
understood as 'keeping quiet' in the sense that when the premisses are asked, the respondent openly accepts them, taking them to be true as the

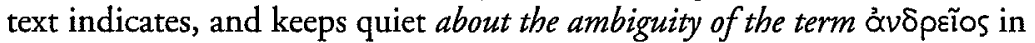

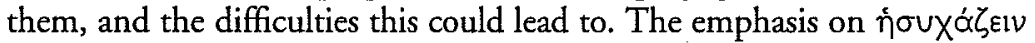
can here be understood as meant to alert one to the contrast with Aristotle, who, as we have seen, asks the answerer to point out any ambiguities immediately when the premisses are asked. ${ }^{86}$ It could have been either the Stoics themselves, or Simplicius, who used the phrasing 'to be silent' to delimit the Stoic position from Aristotle's.

83 (I) Legem esse aiunt disciplinae dialecticae, si de quapiam re quaeratur disputeturque atque ibi quid rogere, ut respondeas, tum ne amplius quid dicas, quam id solum, quod es rogatus, aut aias aut neges; eamque legem qui non servent et aut plus aut aliter, quam sunt rogati respondeant, existumantur indoctique esse disputandique morem atque rationem non tenere. (2) Hoc quidem, quod dicunt, in plerisque disputationibus procul dubio fieri oportet . . . (4) Sed enim esse quaedam videntur, in quibus, si breviter et ad id, quod rogatus fueris, respondeas, capiare ... (I2) Sed huiuscemodi respondisio non fit ex ea lege, quam diximus; plus enim, quam quod rogatus est, respondet. (I3) Et propterea id quoque ad eam legem addi solet non esse captiosis interrogationibus respondendum.

84 The respondent is meant to fall silent when confronted with the Horn Fallacy: 'If you haven't lost something, you have it. But you haven't lost horns. Therefore you have horns.' I discuss the details of this case in another paper.

8s The meaning of jouXó $\zeta_{\ell 1 \nu}$ is not technical in the passages on the Sorites, it just means what it usually means: being silent. The use as a - third - legitimate response in dialectical discourse could perhaps be regarded as technical.

86 This interpretation, I believe, squares with the reading of the text giving by Ebbesen I981: I, 3I-2; however, Ebbesen does not note that the reason why Simplicius' Stoics (or Simplicius), put the advice the way they do may have been that they wished to distinguish their (the Stoic) position from Aristotle's.

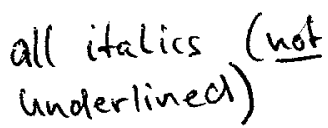


A translation-cum-explication of the passage would then go like this:

In the case of syllogisms based on a homonymy the logicians advise us to be silent <with respect to pointing out the possibility of fallaciousness> until the questioner transfers the <ambiguous> word to another meaning; e.g. if someone asked whether the garment is $\{$ manly/for men\}, if it happens to be for men, we will concede this. <And we are silent about the fact that ' $\{$ manly/for men $\}$ ' is ambiguous, and can also mean manly.> And if he asks whether that which is $\{$ manly/for men $\}$ is courageous, we will concede this, too, for it is true. $<$ Again, we are silent about the fact that ' $\{$ manly/for men\}' is ambiguous, and can also mean for men.> But when he infers that the garment is therefore courageous, $<$ they advise us $><$ to cease to be silent about the ambiguity and $>$ to separate the homonymy of the word ' $\{$ manly/for men $\}$ ' and show that it is said/intended in one way in the case of the garment, in another in the case of the one who has manliness.

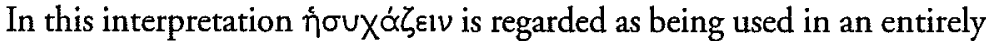
non-technical way. It does not mean what it means in the case of the Sorites (and in the above cited passages in Sextus, Plutarch and Gellius), i.e. not answering the questioner, and thus ending the game on the object level, in order to climb onto a meta-level to explain the fallacy. Rather it is intended to mean keeping quiet with respect to the homonymy, in contrast with

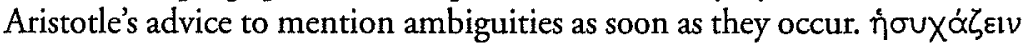
is a common enough Greek word for this to be possible; ${ }^{87}$ and there are many cases in which the Stoics use one and the same word sometimes in a technical or semi-technical way, sometimes in its ordinary, common usage. $^{88}$

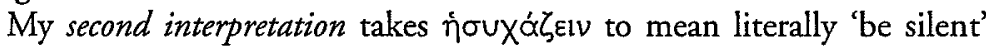
and to refer to the respondent's not answering the questioner when he asks approval for the conclusion, and thus at that point stepping out of the game. ${ }^{89}$ The contrast is not with Aristotle, but with playing the dialectical yes/no game, as it is exemplified in the Gellius passage quoted above. The strategy is the same that Gellius describes as one to be used in the case of

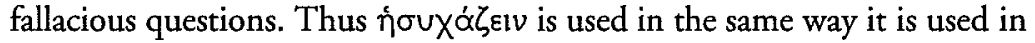
the Gellius, Sextus and Plutarch passages mentioned. ${ }^{90}$ In order to make

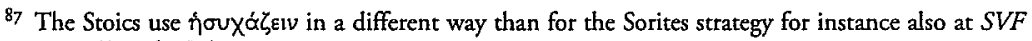
2.500 (Simpl. Cat).

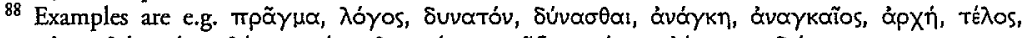

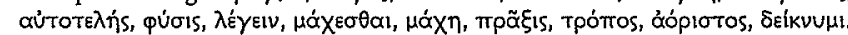

89 As I said above, I do not think the dialectical game continued once the respondent fell silent instead of answering 'yes' or 'no' to a question.

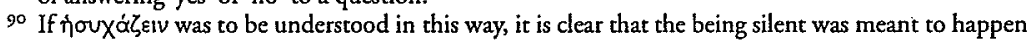
at the point of the conclusion. For in the Stoic view the premisses asked are nor fallacious, but true; cf. section 4 . 
Pr: GQZ

05218418xXco8.xml CU1987B-Frede December 9, $2004 \quad 14: 4$

270

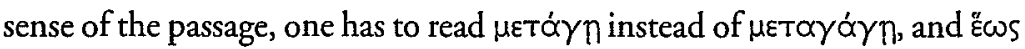
needs to be translated as 'while'. ${ }^{\mathrm{r}}$

In this case, a translation-cum-explication of the passage would rather be as follows:

In the case of syllogisms based on a homonymy the logicians advise us to be silent $<$ i.e. not answer the questioner any more $>$ while the questioner transfers the word onto another meaning; e.g. if someone asks whether the garment is \{manly/for men\}, if it happens to be manly, we will concede this <and thus not be silent>. And if he asks whether that which is $\{$ manly/for men $\}$ is courageous, we will concede this, too, for it is true <and again will thus not be silent $>$. But if he infers that the garment is therefore courageous, <they advise us $><$ to be silent, i.e. not answer anymore, and instead expressly $>$ to separate the homonymy of the word ' $\{$ manly/for men $\}$ ' and show that it is said/intended in one way in the case of the garment, in another in the case of the one who has manliness.

Can we decide between these two interpretations? I believe not. The first

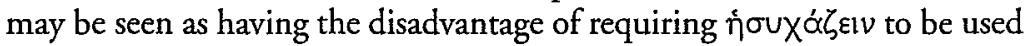
in a different way than in the Sorites. But then it is entirely plausible that the Stoics used it in that way in our particular context. ${ }^{92}$ Moreover, it provides a good contrast to Aristotle. So, someone who favours this interpretation may be more inclined to think that Simplicius presents the view of some later Stoics, Stoics who are acquainted with Aristotle's logic (like those mentioned in Simplicius' Categories who discussed Aristotle's seabattle example). ${ }^{93}$ The second interpretation will make us more inclined to consider this passage as in line with early Stoic or Chrysippean logic, as it works in parallel with what we know about the Stoic treatment of the

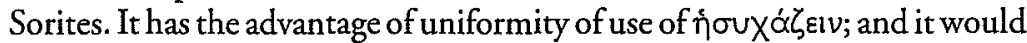
confirm that the Stoics followed one method in dealing with fallacies which have in common that answering 'yes' or 'no' would get the respondent into trouble.

What are the difficulties the respondent would get into in the case of the fallacy of homonymy? Well, having simply agreed to the premisses when they were propounded, if the answerer responded with 'yes' when the conclusion is asked, he would concede something clearly false and thus would have lost the game. On the other hand, if the respondent were to reply 'no' when the conclusion is asked, the questioner would probably

9I Alternatively, for this interpretation, one might want to emend $\varepsilon \omega_{\varsigma}$ to $\omega s$, to be rendered as 'when' or 'as soon as'. Hülser's translation of E̋ws as 'in dem Moment . . . in dem' (Hülser 1987-8: IV, frg. 1257) fits this emendation to ćs.

$9^{2} \mathrm{Or}$, of course, it may have been Simplicius who used that particular word for describing the Stoic method.

93 Simpl. Cat. 406.34-407.5. 
$\mid \begin{aligned} & \text { PI: GQZ } \\ & \text { 052184r8IXco8.xml CUr987B-Frede } \quad \text { December 9, 2004 I4:4 }\end{aligned}$

point out to him that the argument is valid (see section 2 above) and that, having conceded the premisses, the answerer is hence forced to concede the conclusion..$^{94}$ At this point the respondent would need to be able to say: "yes, the conclusion follows, if you assume that the meaning of " $\{$ manly/for men\}" was the same in both premisses, but in fact this is not what we agreed upon earlier'. By responding neither 'yes' nor 'no', but being silent, and then separating the homonymy expressly, the respondent does not agree to an obvious falsehood and provides reasons that will prevent the questioner from scoring points by adducing the - apparent - validity of the argument at this point.

As I cannot give decisive reasons for choosing one interpretation over the other, I leave you with both, for you to select one at your convenience.

\section{THE SCOPE OF THE STOIC METHOD FOR FALLACIES}

\section{OF HOMONYMY}

Aristotle gives two-fold advice to the respondents as to how to proceed in cases of fallacies of homonymy. If they are aware of an ambiguity in a premiss, they are meant to lay it bare as soon as the premiss has been asked. However, in case the ambiguity escapes them and only occurs to them when the conclusion is drawn, they are meant to uncover the ambiguity then.

The Stoic advice is not two-fold; it does not need to be. Their method works with all fallacies of homonymy in single words, as can be shown. First we can state a general requirement for fallacies of homonymy in single words: for such a fallacy to work, it is necessary that in each premiss there is only one reading of the relevant ambiguous word that makes the premiss true, and in at least one premiss the meaning must be different than in the other or others. This can be shown by elimination of all the other possible cases.

If in one of the two sentences proposed as expressing a premiss both meanings of the word led to true propositions, ${ }^{95}$ then no fallacy would ensue. Take an argument with the Greek ambiguous word kưcov, i.e. ' $\{\mathrm{dog} / \mathrm{seadog}\}$ ' in my nomenclature:

If something is a $\{\mathrm{dog} / \mathrm{seadog}\}$, it is an animal.

This is a $\{\mathrm{dog} / \mathrm{seadog}\}$ (pointing at the German shepherd Fido).

Therefore this is an animal (again pointing at the German shepherd Fido).

94 This could again be done in the form of questions.

95 If we imagine fallacies with more than two premisses, we have to say 'in all but one premiss'. 
$\mid \begin{aligned} & \text { Pr: GQZ } \\ & \text { 052184181Xco8.xml } \quad \text { CUr987B-Frede } \quad \text { December 9, 2004 I4:4 }\end{aligned}$

272

S. BOBZIEN

Here the first sentence expresses a true premiss with either reading of $\{\mathrm{dog} / \mathrm{seadog}\} .{ }^{66}$ The respondent hence cannot go wrong by agreeing, even though it is not quite clear what he would be agreeing to, if he says just 'yes' ${ }^{77}$ More importantly, he would go wrong if he said 'no'. The conclusion of the 'argument' is true, harmless, unobjectionable; hence we should not assume the respondent to want to deny it. Can we imagine the respondent (following the Stoic method) to balk at the drawing of the conclusion and to say 'no, the conclusion does not follow - the premisses are unconnected'? If we generalise the Stoic approach slightly, then the answer is 'no'. (Of course there is no evidence that the Stoics considered arguments like the one under discussion.) All we have to do is to take as context of $\{\mathrm{dog} / \mathrm{seadog}\}$ not just each premiss individually, but the two premisses together. Thus by agreeing to the first question, the interlocutor knows he has not made a mistake, whichever way he might take it. At the point when the second premiss is introduced, the context would almost automatically be regarded to be the two premisses taken together, and at that point a mental process of disambiguating in favour of 'dog' takes place, as this is the only reading that is promising for a proper (valid and sound) argument. ${ }^{98}$ Thus the assumption here is no longer only that obvious truth serves as guidance, but also that obvious connectedness of the premisses serves equally as a guide. (We can again imagine some sort of theory of implicature at work here; e.g. something like: 'if you are asked questions, base your answer on the assumption that the argument is valid'.) If this is so, the answerer cannot reasonably deny the conclusion.

What if the two possible readings are true in both sentences that purport to express a premiss???

If $\{$ dogs/seadogs $\}$ are animals, then $\{$ dogs/seadogs $\}$ are living beings.

But $\{$ dogs/seadogs $\}$ are animals.

Therefore $\{$ dogs/seadogs $\}$ are living beings.

Here we have no context that allows disambiguation, but again the sentence that expresses what is concluded is harmless, and there is no reason for the interlocutor to hold back consent at any time. ${ }^{\text {I00 }}$

${ }^{96}$ kúw has actually a third and a fourth meaning in Greek, the dogstar (if that is a separate meaning), and the fetlock-joint of a horse, both of which I will ignore here for reasons of simplification of the examples.

97 How many questions would the Stoics think the questioner asks? To how many questions would they think the answerer responds? Would this depend on the intention of speaker or listener? Would they say this is so in the case of utterances, tokens of (what looks like) a question? What if intention of speaker and listener differ? A host of problems opens up here, not surprisingly.

${ }^{98}$ A further question suggests itself here: can one temporarily leave open which meaning is intended?

99 Or all, if we consider fallacies with more than two premisses.

100 All the questions of note 78 recur here and remain unanswered. 
What, finally, if there are no readings which make all premisses true?

If something is a $\{\mathrm{dog} / \mathrm{seadog}\}$, then it is a plant.

This is a $\{\mathrm{dog} / \mathrm{seadog}\}$ (pointing at Fido or at some seadog).

Therefore, this is a plant (again pointing at Fido or at some seadog).

In this case the answerer is not going to agree to the sentence purported to express the first premiss (no matter what reading). Hence the complex of sentences purported to express an 'argument', whether fallacious or not, does not get off the ground to start with.

Thus the above-mentioned requirement holds: a fallacy of homonymy proper presupposes that in either premiss sentence there is exactly one reading of the ambiguous word that makes the sentence express a true proposition; and that these are two different readings. ${ }^{\text {ror }}$ And as this kind of fallacy is covered by the Stoic method or advice, it follows, that the Stoic method or advice that Simplicius reports works in all cases. ${ }^{102}$

${ }^{10 t}$ The same holds mutatis mutandis for multiple premiss 'arguments'.

${ }^{102}$ I wish to thank Myles Burnyeat and Catherine Atherton for most helpful comments on a draft of the paper and the editors for their patience and generosity. 